\title{
Student Nurse Perceptions of Gypsy Roma Travellers; A European Qualitative Study
}

Vanessa Heaslip, PhD, MA, BSc (Hons), DipHE, DN, RN. Principal Academic \& Deputy Head of Research, Department of Nursing Bournemouth University, United Kingdom and Visiting Associate Professor University of Stavanger, Norway.

Tel: +44 1202 961774, Email: vheaslip@bournemouth.ac.uk Twitter:@HeaslipVanessa

Valerie Vanceulebroeck, MSc, BSN, staff member of the Department of Nursing, AP University College, Antwerp,

Tel: +32 322033 24, Email: valerie.vanceulebroeck@ap.be

Indrani Kalkan, PhD, MS, BSc (Hons), Vice Dean for Faculty of Health Sciences, Istanbul Aydin University, Turkey.

Tel: +90 5332237755 Email: indranikalkan@aydin.edu.tr

Nuran Kömürcü, PhD, MS, BSc (Hons), Head of the Department of Nursing, Faculty of Health Sciences, Istanbul Aydin University, Turkey.

Tel: +90555 2247378 Email: nurankomurcu@aydin.edu.tr

Isabel Anton Solanas, PhD, MSc, BSc (Hons), DipHE, RN. Vice Dean for Internationalisation, Faculty of Health Sciences, Universidad San Jorge, Zaragoza (Spain).

Tel: +34 622248 610, Email: ianton@usj.es Twitter: @IsaAntSol

Acknowledgements: The authors wish to acknowledge and thank the students who participated in this research and shared who their thoughts and experiences

Funding Statements: This research did not receive any specific grant from funding agencies in the public, commercial, or not-for-profit sectors.

\begin{abstract}
Background; Gypsy Roma Travellers are Europe's largest ethnic minority group. Yet they remain one of the most stigmatised communities who have significant health inequalities. Whilst nurses have a role in promoting health access, there have been minimal studies exploring health care
\end{abstract}


professionals' attitudes towards these communities and no studies exploring nursing students' perceptions.

Objectives; To explore nursing students understanding, knowledge and perceptions of working with Gypsy Roma Travellers

Participants; 23 nursing students from across four European countries (UK, Spain, Belgium, Turkey) participated in the study. The students ages ranged between 19-32 year old, there was a mix of students between year one to year three of their programme and both male $(n=3)$ and female students $(n=19)$.

Methods; This qualitative research utilised focus groups and one to one interviews based at the four different universities, all following a pre-agreed interview schedule. Focus groups and interviews were conducted by the research team in the students' first language and later translated into English for analysis using thematic analysis. The COREQ criteria were used in the reporting of the study.

Results; Four themes were identified which included: Exposure to Gypsy Roma Traveller Communities, Perceptions of Gypsy Roma Traveller cultures, Unhealthy lifestyles and culture and Nursing Gypsy Roma Travellers.

Conclusions; Although personal and professional contact with Gypsy Roma Travellers was limited, most of the students' perceptions of these communities were negative. Nurse educational programmes need to embed transformational learning opportunities enabling student nurses to critically reflect upon values and beliefs of Gypsy Roma Travellers developed both before and during their nursing preparatory programme if they are to work effectively in a respectful, culturally sensitive way. There is also generally, a lack of research focussing upon healthcare professionals' attitudes towards these communities that needs to be explored through further research.

Keywords; Healthcare Disparities, Roma, Gypsy, Nurses, Student Nurses, Perceptions, Attitudes, Education

\section{BACKGROUND}

Gypsy Roma Travellers (GRT) is an umbrella term used to denote different Gypsy Traveller ethnic minority communities including Romany Gypsies, Irish Travellers, Welsh Gypsies, Eastern and European Roma; for full explanation see Heaslip et al. (2016a). There are about 10-12 million Gypsy Roma Travellers across Europe (European Commission 2010). Yet these communities often face stark inequalities which remain largely invisible and ignored by wider agendas (Equality and Human Rights Commission (EHRC) 2016). For example, statistical data regarding Gypsy Roma Travellers is not collected within the UK, Turkey, Belgium or Spain, which makes it difficult to track health and illness 
patterns within these communities. There are, however, numerous studies such as Inclusion Health (Aspinall 2014) which identified Gypsy Roma Traveller communities as vulnerable to poorer health status and outcomes. There is evidence within the UK and internationally (Földes and Covaci 2012; Cook et al. 2013) that these communities experience poorer physical health than that of the general population (Goward et al. 2006). A study in the UK by Parry et al. (2007) identified that Gypsy Roma Travellers reported poorer health status over the preceding year than their age sex matched counterparts from the broader community, and were significantly more likely to have a long-term illness, health problems or disability. The most recent data (Office for National Statistics (ONCS) 2014) identified that Gypsies and Irish Travellers reported the lowest general health (70\% rated their health as 'good' or 'very good' compared to $81 \%$ of the overall population). When comparing life expectancy, there is a mixed pattern. In Spain, the life expectancy for Roma is 7 years lower than the general population (European Commission 2014), in Belgium, life expectancy is 10 years lower (Peña-Casas et al. 2011) whilst in the UK life expectancy is 11 years lower for Gypsy Roma Travellers (EHRC 2016). It is difficult to estimate life expectancy for Roma in Turkey as little concrete information exists about their current health problems (Ekmekçi 2016).

Poorer health status and outcomes may be in part due to fatalistic beliefs regarding health and ill health which can make health promotion initiatives more challenging (Van Cleemput et al. 2007). However, provision and access to preventative primary care services also contribute to the picture of inequity and inequality. Research by Peters et al. (2009) identified that only 69\% of GRT were permanently registered with a General Practitioner, highlighting a gap in provision for about $31 \%$ of this population. Even when GRT can access services there is evidence that these services may not be appropriately equipped to meet the needs of these vulnerable communities. Gypsy Roma Travellers also experience being marginalised; indeed they are one of the most vilified ethnic minority groups, who experience huge levels of discrimination across Europe (Heaslip 2016a, Luna-Firebaugh 2013, Rosário et al. 2017; Kende et al. 2017). Research by Aiello et al. (2018) into barriers faced by Roma in accessing health care systems in Spain noted obstacles at two levels; in interactions with healthcare professionals and secondary institutional arrangements which prevented equal access. Whilst research by Francis (2013) exploring health professionals perceptions of these communities, identified limited cultural understanding, knowledge of health needs or issues affecting them as well as poor perceptions that were largely influenced by negative media stereotypes.

Nurses are the largest professional health workforce (All-party parliamentary group 2016); as such they have a key role in ensuring health access and promoting health. They are often the first and 
indeed maybe the only health professional that people see which places them in the unique position of becoming involved in local communities, seeing the culture, strengths and vulnerabilities, all of which enables them to have a role in promoting health access and addressing health inequalities. However there is evidence that GRT experience discrimination in healthcare services (Heaslip 2016b) and reasons for this are multi-faceted including differing world views (Wilson et al. 2018). To date there has been no exploration of student nurses perceptions of working with Gypsy Roma Travellers and this study proposes to address this gap.

\section{$\underline{\text { METHODS }}$}

$\underline{\text { Aim }}$

To explore nursing students understanding, knowledge and perceptions of working with Gypsy Roma Travellers from four Higher Education Institutions, namely Belgium, Turkey, Spain and the UK.

\section{$\underline{\text { Participants }}$}

A purposeful sampling strategy was utilised to recruit to the study in that all students who were attending a Transcultural Summer School were invited to participate in the research. Each of the students who were attending the summer school was sent an email regarding the research by the academic lead for the summer school in each respective university.

\section{Methods}

The COREQ reporting guidelines (Tong et al. 2007) were used in both the framing and reporting of this study. As the research wished to illicit the students understanding, knowledge and perceptions of working with Gypsy Roma Travellers qualitative methodology was chosen. This was appropriate as the purpose of qualitative research is to explore experience, meaning and perspectives of participants (Hammarberg et al. 2016), in this case heath care students. Data were collected through focus groups and one to one interviews lasting between 30-45 minutes. The majority of the data was collected through focus group methods however; if participants were unable to attend a focus group then one to one interviews occurred. Focus groups and one to one interviews were chosen because they can elicit rich, culturally grounded insights into people's experiences (Bowleg 2017). Both the focus groups and one to one interviews were undertaken in the same way, ensuring consistency in data collection. They occurred either in a classroom or meeting room at the participant's university for ease for the students, with the door closed to ensure privacy. The focus groups and one to one interviews were undertaken by the research team; in the UK by VH, Spain by IAS, Belgium by VV and Turkey by IK and NK. Focus group and interviews were undertaken in the students own language to 
make it easy for participants to express their thoughts and experiences. All of the data were audio recorded and transcribed verbatim. Results from Belgium, Turkey and Spain were later translated into English by the research team member undertaking the interview (IAS for Spain, VV for Belgium and IK for Turkey), all of which were fluent in English. The researchers undertaking the focus group and one to one interviews are experienced health professional educators from nursing (VH, IAS, VV, and NK) or nutrition (IK) backgrounds. In addition, they are all experienced researchers who have undertaken extensive research training; four have doctorates (VH, IAS, IK, and NK) and one has an MSc (VV). All of the researchers agreed and used the same focus group guide developed by VH (see table 1).

Table 1 Topic Guide for focus groups

Main Question:

We are interested in hearing about your experiences of working with individuals from Gypsy Roma Travelling communities. Please can you tell us about any experiences you have had to date? (Some of the students may not have had any experiences, if not then please go on to the following questions)

\section{Follow up questions}

- Can you tell us how much you know about Gypsy Roma Traveller communities and what their lives are like?

- What words do you associate with Gypsy Roma Travellers?

- How do you feel about nursing Gypsy Roma Travellers and what influences these feelings?

- Why do you think Gypsy Roma Travellers have poorer physical and mental health and die earlier than people outside of the community?

- How are Gypsy Roma Travellers perceived within your country and does this affect the relationship nurses have with them?

\section{Ethical Issues}

Ethical approval was obtained from the Bournemouth University Research Ethics Committee. As previously noted participants were recruited from students across the four universities participating in a Transcultural Summer School. As such, some of the students knew the academic staff involved in the research as they were involved in the students' programme of study and therefore may have taught the students previously. However, not all the students had met the academic staff before. In the introductory email it was made clear that the proposed research was separate to both their studies and their participation in the summer school. Participants were provided with both a 
participation information sheet, which clearly stated the risk and benefits of participating and noted that participation in the research was completely voluntary, as well as a consent form which they signed. Both the information sheet and consent form stressed the confidential nature of the students' responses as well as their voluntary involvement in the study.

\section{Analysis}

Anonymised transcripts were analysed thematically using a deductive approach to identify patterns and themes across the data set (Braun and Clark 2006) by VH. This included familiarising oneself with the data through repeating reading, searching for meanings and patterns within each focus group/interviews. Following this was the identification of initial codes within each of the focus groups/ interviews, and initial themes from reviewing the codes across the whole data set which was shared with two other researchers (VV, IAS), to discuss and explore. At this stage there was a reviewing and rewriting of themes leading to the identification of these which were shared and explored across the research team to ensure cognisance with the raw data. Transcripts were not sent back to participants for member checking as a narrative review by Thomas (2017) identified no evidence that routine member checks enhanced the credibility or trustworthiness of qualitative research. Instead, credibility was ensured through the sharing of the data analysis with all members of the research team.

\section{FINDINGS}

30 students were approached to participate in the study and from this 25 students ( $n=23$ nurses, $n=2$ dietician students) chose to be involved from across the four Higher Academic Institutions in UK, Turkey, Spain and Belgium. This paper only focuses upon the data from the nursing students $(n=23)$ (See Table 2). Of these 25 students, 22 were involved in focus groups and three were one to one interviews ( $n=1$ Spain and $n=2$ UK), we have not identified these participants in Table 2 to promote the participants' anonymity. Whilst the majority of the participants were female $(n=20)$ compared to males $(n=3)$, this reflects the wider nursing population as around only $10 \%$ of the profession are male (World Health Organisation 2019). The age range of the participants was from 19-32, with the participants from the UK being slightly older than their European counterparts. The students were at different stages of their educational programme from $1^{\text {st }}$ to $3^{\text {rd }}$ year, remembering that the UK programmes is 3 years compared to the other European countries which have a 4 year nursing degree. 
Table 2 Profile of Participants

\begin{tabular}{|c|c|c|c|c|c|}
\hline Code & Country & Age & Gender & Programme of Study & Year of Programme \\
\hline $\mathrm{P} 1$ & UK & 24 & Female & BSc (Hons) Nursing (Adult) & $2^{\text {nd }}$ Year \\
\hline $\mathrm{P} 2$ & UK & 24 & Female & BSc (Hons) Nursing (Adult) & $2^{\text {nd }}$ Year \\
\hline P3 & UK & 32 & Female & BSc (Hons) Nursing (Adult) & $1^{\text {st }}$ Year \\
\hline P4 & UK & 25 & Male & BSc (Hons) Nursing (Adult) & $2^{\text {nd }}$ Year \\
\hline P5 & UK & 20 & Male & BSc (Hons) Nursing (Adult) & $2^{\text {nd }}$ Year \\
\hline P6 & UK & 20 & Female & BSc (Hons) Nursing (Adult) & $2^{\text {nd }}$ Year \\
\hline P7 & Belgium & 22 & Female & Bachelor Nursing & $2^{\text {nd }}$ Year \\
\hline P8 & Belgium & 27 & Male & Bachelor Nursing & $1^{\text {st }}$ Year \\
\hline P9 & Belgium & 21 & Female & Bachelor Nursing & $1^{\text {st }}$ Year \\
\hline P10 & Belgium & 20 & Female & Bachelor Nursing & $1^{\text {st }}$ Year \\
\hline P11 & Belgium & 21 & Female & Bachelor Nursing & $1^{\text {st }}$ Year \\
\hline P12 & Belgium & 20 & Female & Bachelor Nursing & $1^{\text {st }}$ Year \\
\hline P13 & Belgium & 20 & Female & Bachelor Nursing & $1^{\text {st }}$ Year \\
\hline P14 & Spain & 21 & Female & BSc Nursing & $3^{\text {rd }}$ Year \\
\hline P15 & Spain & 21 & Female & BSc Nursing & $3^{\text {rd }}$ Year \\
\hline P16 & Spain & 21 & Female & BSc Nursing & $3^{\text {rd }}$ Year \\
\hline P17 & Spain & 19 & Female & BSc Nursing & $2^{\text {nd }}$ Year \\
\hline P18 & Spain & 22 & Female & BSc Nursing & $2^{\text {nd }}$ Year \\
\hline P19 & Spain & 19 & Female & BSc Nursing & $2^{\text {nd }}$ Year \\
\hline P20 & Turkey & 21 & Female & BS Nursing & $3^{\text {rd }}$ year \\
\hline P21 & Turkey & 21 & Female & BS Nursing & $3^{\text {rd }}$ year \\
\hline P22 & Turkey & 22 & Female & BS Nursing & $3^{\text {rd }}$ year \\
\hline $\mathrm{P} 23$ & Turkey & 21 & Female & BS Nursing & $3^{\text {rd }}$ year \\
\hline
\end{tabular}

Four themes were identified which included: Exposure to Gypsy Roma Traveller Communities, Perceptions of Gypsy Roma Traveller cultures, Unhealthy lifestyles and culture and Nursing Gypsy Roma Travellers.

\section{Exposure to Gypsy Roma Traveller Communities}

Exposure to working with members from Gypsy Roma Traveller communities was mixed across the participants. None of the students from Turkey or UK had any professional exposure; in contrast only 2 of the Belgium participants and all the Spanish participants had come across members of these 
communities in their capacity as student nurses. For the students who had not had any professional exposure, some of them had exposure through their personal lives such as in their local communities or through their childhood:

"I do think I'm friends with a Gypsy on Facebook, because I often see \#gypsy, but I don't know her personally" (P9 Belgium Female)

"I used to have a classmate in school who was a gypsy, and he was such a good person... In fact, they were all really nice, truly, they were all very nice. People didn't want to sit next to them in the refectory, and I used to say to him: "come sit next to me" (P16 Spain, Female)

"I remember there was a GRT child I my school and he was always really aggressive and always getting into fights his family was like...you would never mess with this kid, his family was like really dodgy and stuff and everyone would speak about him and everyone would know him because he was like he was a Gypsy" (P5 UK Male) "In our society naughty children are often warned by saying, "if you continue being naughty/do not sleep, you will be handed over to the gypsies" or "gypsies will take you away in their fardels" (P20 Turkey Female)

\section{Perceptions of Gypsy Roma Traveller Culture}

Even though the majority of the participants had had limited exposure to these cultures, all of them were able to articulate perceptions of Gypsy Roma Traveller cultural values which were largely drawn though social media such as television programmes or films.

"I think the media portrayed it as quite negative, that the stuff that you've seen on TV it can be seen as quite negative and there's been like TV shows on channel 4 the wedding and they were showing how their cultural, the culture of their weddings and how the girls were quite young and the way the boys would be with the girls" (P2 UK, Female)

"I feel really curious about them and, for example, all those programmes on TV, (laughs) "from the street", "gypsy wedding"..." (P15 Spain, Female)

The majority of the cultural values presented were similar irrespective of which country the students came from, focussing upon aspects such as nomadism, extended families, strong family ties, traditional culture where women marry young, staying within ones cultural group and living in caravans.

"They live in a closed community" (P23 Turkey, Female) 
"...they are their own community, a solid group, and a lot with caravans" (P7 Belgium, Female)

"...very tight knit culture, their family, that is a massive priority for them, their very close net- working together and very traditional...they marry very young, it's very traditional they tend to marry within their community" (P4 UK, Male) "They have extended families, they live all together...under the same roof. Big families" (P19 Spain, Female)

However, there were also distinct cultural variations such as in Spain where there is the 'kerchief' test to check for virginity and in Tukey where there was also a distinct focus upon music:

"You know, then there is the wedding, they have to marry really young and once you are married... and the kerchief test and all that" (P14 Spain, Female)

“...they engage in music and dance, there are a couple of famous singers/musicians that I know of, belonging to this community. Other than music, they do not have other fixed professions" (P21 Turkey Female)

Many of the participants articulated a wider societal stigma associated with Gypsy Roma Traveller communities across the four European counties; however, they did not necessarily recognise their own personal negative perceptions. Despite their limited engagement, many of their views regarding these communities were very negative. The negative attributes that were typically identified tended to focus upon criminality, aggressive, violent behaviour or choices made by these communities regarding how they chose to live their lives. These views were influenced by wider societal perceptions as well as personal and professional lived experience:

"In the news you often hear that those people occupy empty houses or empty houses from which the owners are out on holiday" (P11 Belgium, Female)

"...lots of people from where I grew up would associate them with fly tipping which is also criminal activity I guess at a low level" (P3 UK Female)

“And if they have to trick you, they just do; they don't care. They don't mind going to jail for a year in order to get what they want" (P14 Spain Female)

"I know that they are the ones first held responsible or questioned when there is a theft or crime in the vicinity" (P20, Turkey, Female) 


\section{Unhealthy lifestyles and culture}

Within the focus groups and interviews participants were informed that Gypsy Roma Travellers have higher morbidity and mortality than those living outside these communities and the participants were asked their thoughts regarding this. There were a range of views presented including challenges accessing health as well as how their cultures could also precipitate poorer health:

"so it could be their lifestyle... because they might not have access to, because they might not have much money they may not have access to healthy foods stuff like that because I know that it's the less rich you are the earlier you die...because they are quite segregated from the community, I think that plays a big part, they may not access health care. Maybe the way they live, it's quite, not primitive, but I think they're back from the way we live now" (P5 UK, Male)

“Because of their customs... I think most of us don't drink coke, don't eat cheap sausages. We don't take drugs, nor... I mean, obviously, I think everyone takes drugs but, in proportion, gypsies do these things more frequently" (P14 Spain, Female)

"They live in certaın parts/regions of the city, sometimes in the outskirts. They have low socioeconomic status, so they are not able to access quality health service or other needs" (P23, Turkey, Female)

"I also think that the everyday environment of the people plays a role in their health; what they eat, drink... maybe it's not always so clean, for example the water, meat; maybe it's not from a supermarket. I think that also has to do something with it..." (P10, Belgium, Female)

\section{Nursing Gypsy Roma Travellers}

The participants highlighted that not only did society have negative attitudes towards GRT communities; they also had witnessed negative perceptions from their mentors and other registered nurse in practice towards these communities. This typically focussed upon warning them regarding potentially aggressive or violent behaviour as well as nonconcordance with medical treatment:

“... at handover they just warn there will be lots of people all the time and they won't follow say our traditional visitor times... they were not to follow us and there may be trouble" (P20 UK, Female) 
"As far as health care system is concerned, they would not be deprived of the facilities however, heath service providers including nurses may be biased from time to time" (P21 Turkey, Female)

“...in my experience of working with gypsy patients, and I was a student nurse, my mentor used to warn me: "he's gypsy". Like that piece of information was relevant" (P15 Spain, Female) "I do think that if you're in a hospital working with a multidisciplinary team that there will always be one in the team that is prejudiced" (P8 Belgium, Male)

When the participants were reflecting on their practice, whilst many of them acknowledged that their professional code and personal philosophy of nursing was to treat people the same' and not to discriminate, many of them recognised that their perceptions towards Gypsy Roma Travellers could unconsciously influence the way they practiced when working with individuals in these communities:

"Unconsciously yes perhaps, not consciously, but unconsciously for sure" (P15 Spain Female)

"Even though we may seek to give equal healthcare we all have pre-conceptions and I would say if I was in a room with a man or a couple of men from that community I may feel a bit intimated and I would obviously try not to let that affect my practice but from the words and stories we hear about them are generally fairly negative so it would probably affect at least my behaviour" (P3 UK, Female)

"For me being a male and looking after a female at the back of my mind thinking that their culture is the men look after the female and I would be worried they might get annoyed or upset that it is a male nurse looking after their wife or sister whatever it might be that female and that might not be the case but at the back of my mind I would be thinking are they unhappy with a male nurse "(P4 UK, Male) "I think there's a lot of rejection and a lot of prejudice and, at the end of the day that has an impact on us. It's what we have been told at home, and in school, etc. And in the end, even if you don't want to feel like that, you are already prejudiced against them (P16 Spain, Female)

"I would treat them equally as other patients. But for a cross contamination point of view I would be extra careful while treating them. Because of their lifestyle, they 
have a different immune system or endemic diseases compared to ours, so I would like to take this extra precaution" (P22, Turkey, Female)

"I also think that because we don't really know them, that we have more prejudices about them..." (P9 Belgium, Female)

\section{DISCUSSION}

Gypsy Roma Travellers are the largest ethnic minority group within Europe who experience the most extreme segregation and marginalisation from society (European Agency for Fundamental Human Right (FRA) 2014), resulting in drastic health inequalities (Parekh and Rose 2011). In order to address this, the European Union have identified and set minimum standards in the areas of access to education, employment, health and housing (FRA 2014). Despite this, there appears to be little national data collection regarding experiences of ill health of Gypsy Roma Traveller Communities in the four countries included in this research. Implementing systematic data recording mechanisms which identify patterns of illness experienced by Gypsy Roma Travellers could be used to lead and shape targeted healthcare interventions to address healthcare inequity that exists for Gypsy Roma Travellers within Europe.

Nurses have a key responsibility to promote health access for marginalised communities, but only if they are able to establish positive therapeutic relationships with individuals in these communities. The findings from this first study exploring European nursing students' attitudes and perceptions identified there is much work to be done. Whilst the majority of participants had limited formal professional experience of working with Gypsy Roma Travelling communities, they had clear ideas and perceptions regarding them. Whilst some of these perceptions reflected some of the cultural norms of these communities, there were also some very negative perceptions which the participants noted could, and in some cases, did influence their professional practice. Whilst statutory nursing councils (Nursing Midwifery Council 2018; Turkish Nurse Association, 2009; Belgium Royal Decree 78, 1967; Consejo General de Enfermería de España, 1988) and international guidance (International Council of Nurses 2012) assert that nursing professional practice has to challenge discriminatory practice, it is evident that this is not always being reflected in nursing professional practice. Not only did the participants enter their professional programmes with either direct or indirect exposure, but this was perpetuated through their on course exposure which subsequently influenced their professional practice (Figure 1). 


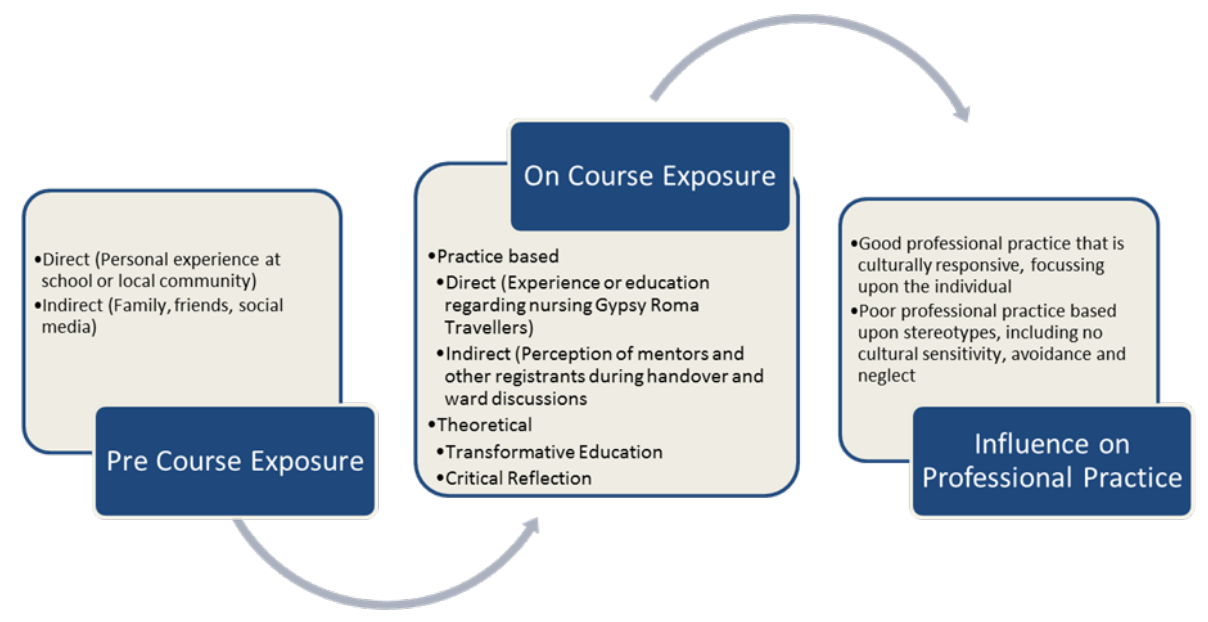

Figure 1 Model presenting development of professional values regarding Gypsy Roma Travellers

Whilst we cannot influence students' pre course exposure, as nurse educators we have the opportunity through theoretical and practical course exposure to challenge and explore students previous and current experiences and perceptions. Aiello et al. (2018) asserts that prejudice and discrimination against Gypsy Roma Travellers can only effectively be reduced by challenging antiRoma bias and exploring and changing perceptions of threat contributing to a more inclusive group identity. Hutchinson et al. (2018) developed a theoretical model for exploring attitudes towards Gypsy Roma Travellers (figure 2).

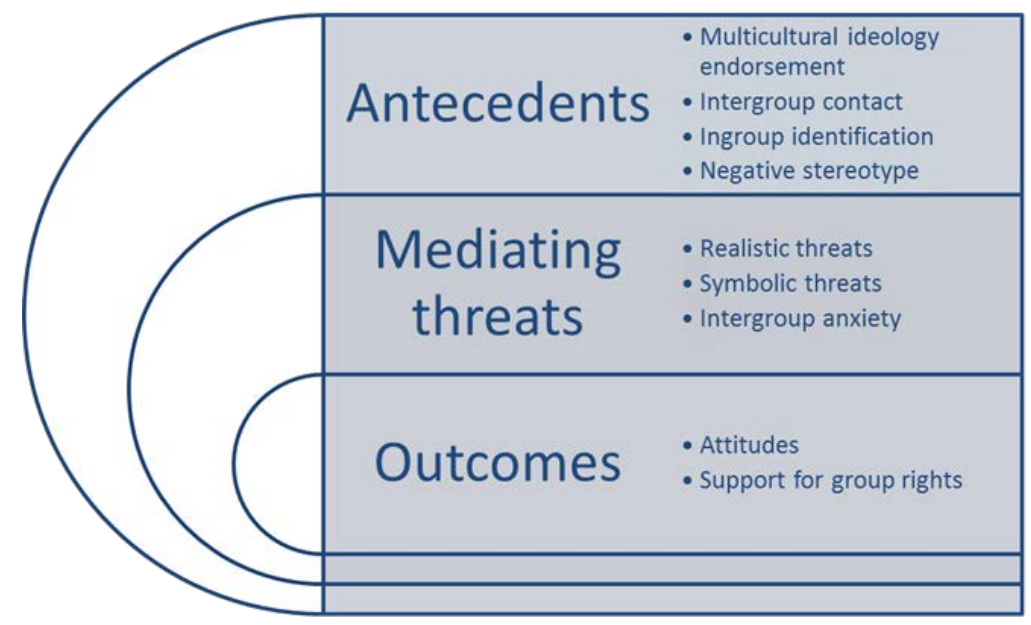

Figure 2 Theoretical Model for predicting public attitudes towards Gypsy Roma Travellers (adapted from Hutchinson et al. 2018) 
As nursing is a values-based profession, we postulate that educational approaches have to consider values as part of the curriculum (Tetley et al. 2016). As part of this there is an opportunity to explore and challenge stereotypes of individuals in these communities, in a positive and safe environment which in turn can reduce anxiety and perceived threat. Using the principles of Transformational Theory (Mezirow 1996, 1997); nurse educators can embed curricula which highlight both "habits of mind' and 'a point of view'. Within the exploration of habits of mind students are encouraged to reflect critically on their habitual ways of thinking, feeling and acting, examining how these have been influenced by cultural, social, educational and political perspectives which they will have articulated in specific points of view, beliefs, values, judgements, and attitudes (Mezirow 1997). We argue here that it is both the role and responsibility of nurse educators to provide student nurses with the opportunity to explore their beliefs and attitudes regarding marginalised groups (in this case Gypsy Roma Travellers) in a safe environment (Heaslip and Ryden 2013) as part of the hidden curriculum. McAllister $(2011 ; 44)$ argues that the value of transformative learning in nursing is in its ability to awaken students "to the issues of injustice that lead to and sustain health inequities and to promote in them critical thinking and questioning of previously held assumptions, beliefs, values, and perspectives, so that they may be part of systemic change". It is this systemic change that we argue will enable health care professionals to begin to address health inequities and enable a more just and equal society.

The challenge for nurse educators is where to locate such educational pedagogy. There are currently no globally agreed expectations of nurse educational programmes which can range from secondary school level to university education and last between two to five years (WHO 2009). In addition, the biomedical bias in nurse education (Zamanzadeh et al. 2015) promotes curricula which focus on biological and pathological aspects of illness reducing opportunities to explore wider socio-political aspects that influence health. This is despite international agreement to work towards meeting the Sustainable Development Goals ((SDG) United Nations 2015) of 'Good Health and Wellbeing' (SDG 3) and 'Reducing Inequalities' (SDG 10). We argue that all nursing preparatory programmes have a moral and professional responsibility to ensure that they run courses/modules which provide students with opportunities to critically reflect and examine wider socio-political aspects of population health and wellbeing. This needs to be introduced at the start of the programme providing opportunities to explore direct/non-direct pre-course perceptions of students and building upon this in latter parts of the programme to examine national and international health inequalities of marginalised communities. As educational curricula needs to be evidence based, evaluating the impact is important and would require mixed method longitudinal study exploring students' 
perceptions at the start and end of their programme of study followed up by ethnographic study exploring nurses' relationships with patients in the clinical area.

\section{Limitations}

We wish to acknowledge the limitations of our research. Firstly, as this is a qualitative study, as such we do not seek generalisability of the findings; instead we argue it is for the reader to identify the transferability of this study to their educational practice and institution. Secondly, as was a selfselecting sample then there could have been an over representation of positive views towards Gypsy Roma Travellers although the findings do not suggest this to be the case. We argue that whilst this paper is focussed on student perceptions of Gypsy Roma Travellers, the findings and discussion could be transferable to other stigmatised and marginalised groups.

\section{Conclusion}

Nurses play a fundamental role in healthcare and we argue that in order to encourage student nurses to feel confident in working and facilitating health access to Gypsy Roma Travellers then their educational programmes need to facilitate the opportunity for individuals to critically reflect upon their values and beliefs. Doing this would enable the students to become respectful, culturally sensitive practitioners. There has been minimal exploration regarding health care professionals' perceptions of Gypsy Roma Travellers, indeed this was the first study of its kind exploring European nursing student perceptions. We argue that this is an under-researched area that has to be addressed to explore whether the negative perceptions noted here are more widespread across the nursing and healthcare professions. We wish to conclude this paper with a quote from one of the students that participated:

"If I were a gypsy and I heard this audio I would start crying, you know? Because this is what people think of me. And I may concede some of the points but... but it is also their past history. I think we have to clean their image, and they are evolving. And society is evolving with them" (P15 Spain, Female).

\section{REFERENCES}

Aiello, E., Fletcha, A., Serradell, O., 2018. Exploring the barriers: a qualitative study about the experiences of Mid-SES Roma navigating the Spanish healthcare system. International Journal of Environmental Research and Public Health 15(2), pii: E377 
All-Party Parliamentary Group on Global Health, (2016). Triple Impact; how developing nursing ill improve health, promote gender equality and support economic growth. London: All-Party Parliamentary Group on Public Health

Aspinall, P., 2014. Hidden Needs; Identifying Key Vulnerable Groups in Data Collections: Vulnerable Migrants, Gypsies and Travellers, Homeless People and Sex Workers: Inclusion Health.

Belgian Royal Decree 78, 10 NOVEMBER 1967. - [Koninklijk besluit $\mathrm{nr} 78$ betreffende de uitoefening van de gezondheidszorgberoepen] <W 2001-08-10/49, art. 27; 022; Inwerkingtreding : 0109-2001>., Replaced by the coordinated law of 10 may 2015 in the exercise of health professions.

Bowleg, L., 2017. Towards a critical health equity research stance: Why epistemology and methodology matter more than qualitative methods. Health Education and Behaviour 44(5), $677-684$

Braun, V. and Clarke, V., 2006. Using thematic analysis in psychology. Qualitative Research in Psychology 3, 77-101

Consejo General de Enfermería de España., 1988. Código deontológico de la enfermería española. Comisión Deontológica, Ilustre Colegio Oficial de Enfermería de Zaragoza. Available: https://www.ocez.net/archivos/comision/213-codigocge.pdf [accessed 17 February 2019]

Cook, B., Ferris Wayne, G., Valentine, A., Lessios, A. and Yeh, E., 2013. Revisiting the evidence on health and health care disparities among Roma: A systematic review 2003-2012. International Journal Public Health 58, 885-911.

Ekmekçi. P., 2016. Health and Roma People in Turkey. Balkan Medical Journal 33(4), 377-382 Equality and Human Rights Commission. 2016. England's most disadvantaged groups: Gypsy, Travellers and Roma, is England fairer? Review spotlight Report, EHRC Manchester. Available from https://www.equalityhumanrights.com/en/publication-download/englands-mostdisadvantaged-groups-england-fairer-spotlight-reports [accessed 11 February 2019]

European Agency for Fundamental Human Right. 2014. Roma survey - data in focus. Poverty and employment: the situation of Roma in 11 EU Member States. Luxembourg: Publications Office of the European Union

European Commission. 2014. Roma Health Report Health status of the Roma population Data collection in the Member States of the European Union, available from https://ec.europa.eu/health/sites/health/files/social determinants/docs/2014 roma healt h report es en.pdf [accessed 11 February 2019]

European Commission. 2010. Communication from the Commission to the Council, the European Parliament, the European Economic and Social Committee and the Committee of the 
regions. Available from http://eur-lex.europa.eu/legalcontent/EN/TXT/?qid=1444909812175\&uri=CELEX:52010DC0133 [accessed 11 February 2019]

Földes, M. and Covaci, A., 2012. Research on Roma health and access to healthcare: state of the art and future challenges. International Journal Public Health 57, 37-39.

Francis, G., 2013. Developing the cultural competence of health professionals working with Gypsy Travellers. Journal of Psychological Issues in Organisational Culture 3, 64-77

Goward, P., Repper, J., Appleton, L. and Hagan, T., 2006. Crossing Boundaries. Identifying and meeting the mental health needs of Gypsies and Travellers. Journal of Mental Health 15 (3), 315-327.

Hammarberg, K., Kirkman, M., de Lacey, S., 2016. Qualitative research methods: when to use them and how to judge them. Human Reproduction 31(3); 498-501

Heaslip, V., Hean, S. and Parker, J., 2016a. Lived experience of vulnerability from a Gypsy Roma Traveller Perspective. Journal of Clinical Nursing 25, 1987-1998.

Heaslip, V., Hean, S., \& Parker, J. 2016b. The etemic model of Gypsy Roma Traveller community vulnerability: Is it time to rethink our understanding of vulnerability? Journal of Clinical Nursing 27 (17-18), 3426-3435

Heaslip, V., Ryden, J., 2013 (eds). Understanding Vulnerability; A Nursing and HealthCare Approach (EDS). Oxford: Wiley Blackwell.

Hutchison, P., Chihade, R., Puiu, A., 2018. Predictors of "the last acceptable racism": group threats and public attitudes toward Gypsies and Travellers. Journal of Applied Social Psychology 48, 237-247

International Council of Nurses. 2012. The ICN code of ethics for nurses. Geneva: ICN

Kende, A., Hadarics, M., Láśticová, B., 2017. Anti-Roma attitudes as expressions of dominant social norms in Eastern Europe. International Journal of Intercultural Relations 60, 12-27

Lana-Firebaugh, E., 2013. American Indians and the Pavee of Ireland; the struggle for selfdetermination through fair and accountable police services. American Indian Quarterly 37 (4), 317-339

McAllister, M., 2011. STAR: A transformative learning framework for Nurse Educators. Journal of Transformative Education 9(1), 42-58

Mezirow, J., 1997. Transformative Learning: Theory to Practice. New Directions for Adult and continued education $74,5-12$

Mezirow, J., 1996. Contemporary Paradigms' of learning. Adult Education Quarterly 46(3) 158-173 
Nursing Midwifery Council. 2018. The Code; Professional standards of practice and behaviour for nurses, midwives and nursing associates. London: Nursing Midwifery Council

Parekh, N., Rose, T., 2011. Health Inequalities of the Rom in Europe: A literature Review. Central European Journal of Public Health 19 (3) 139-142

Parry, G., Van Cleemput, P., Paters, J., Walters, S., Thomas, K. and Cooper, C., 2007. Health Status of Gypsies and Travellers in England. Journal of Epidemiol Community Health 61, 198-204.

Peña-Casas, R. Ghailani, D. Nicaise, I. 2011. Promoting the Social Inclusion of Roma A Study of National Policies: Belgium. 44 Cijfers pric Limburg 2009,

Peters, J., Parry, G., Van Cleemput, P., Moore, J., Cooper, C. and Walters, S., 2009. Health and use of health services: a comparison between Gypsies and Travellers and other ethnic groups. Ethnicity and Health 14 (4), 359-377.

Office for National Statistics. 2014. 2011 Census analysis: What does the 2011 Census tell us about the characteristics of Gypsy or Irish travellers in England and Wales? Available from: https://www.ons.gov.uk/peoplepopulationandcommunity/culturalidentity/ethnicity/articles Lwhatdoesthe2011censustellusaboutthecharacteristicsofgypsyoririshtravellersinenglandand wales/2014-01-21 [accessed 11 February 2019]

Rosário, P., Núñez, J., Vallejo, G., Azevedo, R., Pereira, R., Moreira, T., Fuentes, S., Valle, A., 2017. Promoting Gypsy children's behavioural engagement and school success: Evidence from a four-wave longitudinal study. British Educational Research Journal 43(3), 554-571

Tetley, J., Dobson, F., Jack, K., Pearson, B., Walker, E., 2016. Building a values based culture in nurse education. Nurse Education in Practice 16(1), 152-155

Thomas, D., 2017. Feedback from research participants: are member checks useful in qualitative research? Qualitative Research in Psychology 14(1), 23-41

Tong, A., Sainsbury, P., Craig, J., 2007. Consolidated criteria for reporting qualitative research (COREQ): a 32-item checklist for interviews and focus groups. International Journal for Quality in Health Care 19 (6), 349-357

Turkish Nurse Association, 2009. Principles of Ethics and Responsibilities of Nurses, Available from: http://www.turkhemsirelerdernegi.org.tr/tr.aspx [accessed 18.2.2019]

Van Cleemput, P., Parry, G., Thomas, K., Peters, k. and Cooper, C., 2007. Health related beliefs and experiences of gypsies and travellers: a qualitative study. Journal of Epidemiol Community Health 61, 205-219.

World Health Organisation. 2019. Data and Statistics. Available from http://www.euro.who.int/en/health-topics/Health-systems/nursing-and-midwifery/dataand-statistics [accessed 11th February 2019] 
World Health Organisation. 2009. Global standards for the initial education of professional nurses and midwives. Geneva: World Health Organisation.

Wilson, D., Heaslip, V., Jackson, D., 2018. Improving Equity and Cultural Responsiveness with Marginalised Communities. Journal of Clinical Nursing 27(19-20), 3810-3819

Zamanzadeh, V., Jasemi, M., Valizadeh, L., Keogh, B., Taleghani, F., 2015.Effective Factors in Providing Holistic Care: A Qualitative Study. Indian Journal of Palliative Care 21(2), 214-224 